\title{
Quality of Life and Anxiety before and after Lung Cancer Chemotherapy: Relationship to Patient's Personality
}

\author{
Satoru Nakada, Keiichi NagaO*, Yasuo Takiguchi, Koichiro Tatsumi and Takayuki KurIYama
}

\begin{abstract}
The purpose of the study was to assess the quality of life (QOL) and anxiety in 50 inpatients with primary lung cancer and examine the influence of their personalities on the QOL assessment. We used a psychological personality test to evaluate the patient's personality, then followed the course of QOL and anxiety before and after chemotherapy. To measure QOL, we used Holmes's QOL checklist, and the State-Trait Anxiety Inventory was adopted to estimate the patient's anxiety. Eighty courses of chemotherapy were administered, and QOL evaluations were performed 235 times. By using factor analysis, the somatic, social and psychological factors were extracted which confirmed the reliability and validity of the QOL checklist. The psychological QOL score showed a correlation with A (Adult) and AC (Adapted Child) of the five ego states in the Egogram. Therefore, it is important to survey the patients' personalities in order to grasp their QOL accurately.
\end{abstract}

(Internal Medicine 35: 611-616, 1996)

Key words: quality of life (QOL) checklist, egogram, state-trait anxiety inventory, ego state

\section{Introduction}

It is widely accepted that evaluation of the patient's quality of life (QOL) is indispensable in assessing the condition of those patients who receive chemotherapy for cancer. The assessment of QOL should include the investigation of elements such as somatic sensation, social interaction and psychological state. Most questionnaires for the assessment of QOL include these elements (1). It is considered to be important to follow the course of each of these elements so that an individual patient's QOL can be adequately assessed (2). Most of the reported methods of assessing QOL use the self-entry questionnaire method $(3,4)$. This method relies on patient's subjective judgment and hence inevitably involves the influence of the patient's personality on the QOL assessment, although the extent of the influence varies among patients. Many questionnaires include questions concerning anxiety (psychological state) and the patient-family relationship (social interaction). It is highly likely that even when these questions are given to healthy individuals, the answers will vary. When the questionnaire asks, "Do you feel anxious about your current state?", the answer will probably depend on whether the respondent has pessimistic or optimistic tendencies, even when the respondent is disease-free. Therefore even if two patients' physical condi- tions are the same, their social and psychological QOL scores can vary. These variations may be caused by the differences in patients' personalities. But since it is difficult to examine personality objectively, a small number of such studies have been reported concerning the personalities of patients only at a terminal stage of lung cancer. The significance of the present study is to evaluate the patients' personalities objectively and clarify their relationship to QOL assessment scientifically. If responses to questionnaires are evaluated without considering this aspect, the assessment of QOL involves some risks of error. Although variations of personality will not give rise to any serious problem when the course of QOL is followed in the same patient, caution is required when the QOL is assessed among different patients or groups of patients. It will also be difficult to determine whether the QOL of a given patient is good or bad on the basis of a single questionnaire. The main purpose of the present study was to verify that the patient's personality exerts an influence on QOL assessment. Therefore the study was undertaken to classify patients according to their personalities by Egogram and to follow the course of QOL and anxiety before and after chemotherapy for lung cancer so as to examine the influence of the patient's personality on QOL assessment.

From the Department of Respiratory Medicine, Chiba University School of Medicine and *the Health Sciences Center, Chiba University, Chiba Received for publication October 6, 1995; Accepted for publication May 28, 1996

Reprint requests should be addressed to Dr. Satoru Nakada, the Japanese Association Clinic, Singapore, 820 Thomson Road \#01-03 Mount Alvernia Medical Centre, Singapore 574623, Singapore 


\section{Subjects and Methods}

The subjects consisted of 50 patients with primary lung cancer who received chemotherapy in our institute between October 1991 and September 1993. Their ages ranged between 35 and 78, with the median being 58. Lung cancer was histologically classified as adenocarcinoma in 29 patients, squamous cell carcinoma in 8 and small cell carcinoma in 13 . The clinical stage on admission was IIIA in 7 cases, IIIB in 22 and IV in 21. The Performance Status (PS) on admission was 0 in 4 cases, 1 in 35, 2 in 10 and 3 in 1 . In all 50 cases, cisplatin was included in the regimen of chemotherapy, with antiemetic supportive therapy in the form of methylprednisolone and metoclopramide.

A leaflet describing the purpose of this QOL survey and assuring protection of the patient's privacy was given to the patients upon admission. If they gave informed consent to this QOL monitoring, they received tests using the Egogram, the state-trait anxiety inventory (STAI) and a QOL questionnaire soon after admission. The Egogram, a personality test which uses a questionnaire, is often employed in the field of psychosomatic medicine to gain some understanding of the patient's personality. The STAI is used for assessment of state anxiety (STAI-1) and trait anxiety (STAI-2) (5).

The QOL questionnaire used in this study was a Japanese translation of a slight modification of the Quality of Life Index prepared by Holmes and Dickerson (6) (Table 1). It contains 24 questions concerning physical, psychological and social elements. The respondent marks a point along a $10 \mathrm{~cm}$ line (a visual analog scale) to answer each question (7).

The Egogram and STAI- 2 were used to obtain characteristics of the patient's personality. The preliminary investigation showed the lowest QOL score on the second day of chemotherapy. The QOL survey and the STAI-1 test were carried out before, immediately after (day 2), and three weeks after the commencement of chemotherapy in order to follow the course of QOL and anxiety. The data were subjected to statistical analysis using non-parametric tests, namely, the Spearman rank correlation coefficient, the Wilcoxon signed-rank and the Kruskal-Wallis test.

\section{Results}

A total of 235 data items concerning QOL and state anxiety were gathered before and after 80 courses of chemotherapy in 50 patients. Out of all responses, $0.83 \%$ were invalidated. Each item of the QOL questionnaire was subjected to factor analysis. The factor loadings after varimax rotation indicate that the questions on the QOL questionnaire can be divided into three factors (Factor 1: physical, Factor 2: social and Factor 3: psychological) (Table 2). The construct validity of the QOL questionnaire was confirmed.

An analysis of variance was carried out to assess the relationship between the simultaneously evaluated PS and QOL score in four groups of patients (PS 0, 1, 2 and 3 groups). This analysis revealed significant inter-group differences in each of the
Table 1. QOL Check List

\begin{tabular}{|c|c|c|c|}
\hline 1 & How much pain? & $\begin{array}{l}\text { Worst pain I have } \\
\text { ever had }\end{array}$ & No pain \\
\hline 2 & How much nausea? & $\begin{array}{l}\text { I feel as sick as I } \\
\text { possibly could be }\end{array}$ & I do not feel sick at all \\
\hline 3 & How is your appetite? & $\begin{array}{l}\text { I cannot face } \\
\text { food at all }\end{array}$ & $\begin{array}{l}\text { My appetite is normal } \\
\text { for me }\end{array}$ \\
\hline 4 & How do you sleep? & Could not be worse & Sleep as well as ever \\
\hline 5 & How is your mood? & $\begin{array}{l}\text { Could not feel more } \\
\text { miserable }\end{array}$ & Could not be better \\
\hline 6 & $\begin{array}{l}\text { How do you feel about } \\
\text { your appearance? }\end{array}$ & $\begin{array}{l}\text { The worst it has } \\
\text { ever been }\end{array}$ & $\begin{array}{l}\text { My appearance has } \\
\text { not changed }\end{array}$ \\
\hline 7 & How mobile are you? & $\begin{array}{l}\text { Completely unable to } \\
\text { move my body }\end{array}$ & $\begin{array}{l}\text { Normal level of physical } \\
\text { activity for me }\end{array}$ \\
\hline 8 & How are you bowels? & $\begin{array}{l}\text { My bowel pattern has } \\
\text { completely changed }\end{array}$ & $\begin{array}{l}\text { My bowels are } \\
\text { functioning normally }\end{array}$ \\
\hline 9 & How is your urination? & $\begin{array}{l}\text { Urination has become } \\
\text { very difficult }\end{array}$ & $\begin{array}{l}\text { I am able to pass } \\
\text { urine normally }\end{array}$ \\
\hline 10 & How is your breathing? & $\begin{array}{l}\text { I find breathing } \\
\text { very difficult }\end{array}$ & $\begin{array}{l}\text { My breathing is } \\
\text { perfectly normal }\end{array}$ \\
\hline 11 & $\begin{array}{l}\text { How is your cough and } \\
\text { sputum? }\end{array}$ & Could not be worse & $\begin{array}{l}\text { I have no cough } \\
\text { and sputum }\end{array}$ \\
\hline 12 & How tired do you feel? & $\begin{array}{l}\text { Could not feel } \\
\text { more tired }\end{array}$ & I do not feel at all tired \\
\hline 13 & $\begin{array}{l}\text { How is your level of } \\
\text { activity? }\end{array}$ & $\begin{array}{l}\text { I cannot do anything } \\
\text { I used to do }\end{array}$ & $\begin{array}{l}\text { I can do everything } \\
\text { I used to do }\end{array}$ \\
\hline 14 & $\begin{array}{l}\text { How are your recreational } \\
\text { activities? }\end{array}$ & $\begin{array}{l}\text { I do not take part in my } \\
\text { recreational activities }\end{array}$ & $\begin{array}{l}\text { I continue with my usual } \\
\text { recreational activities }\end{array}$ \\
\hline 15 & $\begin{array}{l}\text { Are you worried about } \\
\text { the future? }\end{array}$ & $\begin{array}{l}\text { I am worried } \\
\text { about the future }\end{array}$ & $\begin{array}{l}\text { I am not particularly } \\
\text { worried about the future }\end{array}$ \\
\hline 16 & $\begin{array}{l}\text { Are you worried about } \\
\text { your future ability to earn? }\end{array}$ & $\begin{array}{l}\text { I am worried about my } \\
\text { future ability to earn }\end{array}$ & $\begin{array}{l}\text { I am not worried about } \\
\text { my future ability to earn }\end{array}$ \\
\hline 17 & Do you feel isolated? & I feel totally isolated & I do not feel isolated \\
\hline 18 & $\begin{array}{l}\text { Can you discuss your } \\
\text { feelings with your } \\
\text { family? }\end{array}$ & $\begin{array}{l}\text { I cannot discuss my } \\
\text { feelings with my family }\end{array}$ & $\begin{array}{l}\text { I can discuss my feelings } \\
\text { with my family }\end{array}$ \\
\hline 19 & $\begin{array}{l}\text { How is your relationship } \\
\text { with your roommates? }\end{array}$ & $\begin{array}{l}\text { I do not have good relation- } \\
\text { ships with my roommates }\end{array}$ & $\begin{array}{l}\text { I have good relationships } \\
\text { with my roommates }\end{array}$ \\
\hline 20 & $\begin{array}{l}\text { Can you discuss anything } \\
\text { with your doctors? }\end{array}$ & $\begin{array}{l}\text { I do not feel I can discuss } \\
\text { anything with my doctors }\end{array}$ & $\begin{array}{l}\text { I can discuss anything } \\
\text { with my doctors }\end{array}$ \\
\hline 21 & $\begin{array}{l}\text { Can you discuss anything } \\
\text { with your nurses? }\end{array}$ & $\begin{array}{l}\text { I do not feel I can discuss } \\
\text { anything with the nurses }\end{array}$ & $\begin{array}{l}\text { I can discuss anything } \\
\text { with the nurses }\end{array}$ \\
\hline 22 & $\begin{array}{l}\text { Do you have something } \\
\text { to live for? }\end{array}$ & $\begin{array}{l}\text { I do not have anything } \\
\text { to live for }\end{array}$ & $\begin{array}{l}\text { I have a great deal } \\
\text { to live for }\end{array}$ \\
\hline 23 & $\begin{array}{l}\text { Are you contented with } \\
\text { your therapy? }\end{array}$ & $\begin{array}{l}\text { I am not contented } \\
\text { with this therapy }\end{array}$ & $\begin{array}{l}\text { I am contented with } \\
\text { this therapy }\end{array}$ \\
\hline 24 & $\begin{array}{l}\text { Are you contented with } \\
\text { your current state? }\end{array}$ & $\begin{array}{l}\text { I am not contented } \\
\text { with things as they are }\end{array}$ & $\begin{array}{l}\text { I am contented with } \\
\text { present situation }\end{array}$ \\
\hline
\end{tabular}


Table 2. Factor Loading of Each Question

\begin{tabular}{llll}
\hline Questions & Factor 1 & Factor 2 & Factor 3 \\
\hline 2. nausea & 0.674 & 0.065 & 0.299 \\
12. tiredness & 0.666 & 0.016 & 0.317 \\
1. pain & 0.659 & 0.136 & 0.269 \\
3. appetite & 0.631 & 0.050 & 0.437 \\
4. sleep & 0.577 & 0.048 & 0.134 \\
14. recreational activity & 0.552 & 0.144 & 0.108 \\
13. activity & 0.535 & 0.135 & 0.195 \\
9. urination & 0.528 & 0.135 & 0.001 \\
10. breathing & 0.505 & 0.139 & 0.135 \\
11. cough and sputum & 0.478 & 0.033 & 0.028 \\
8. bowels & 0.471 & 0.165 & 0.081 \\
7. mobility & 0.453 & 0.166 & 0.426 \\
6. appearance & 0.406 & 0.012 & 0.389 \\
20. discuss with doctors & 0.093 & 0.865 & 0.143 \\
21. discuss with nurses & 0.117 & 0.854 & 0.197 \\
18. discuss with family & 0.135 & 0.788 & 0.182 \\
19. roommates relation & 0.219 & 0.685 & 0.090 \\
23. content with therapy & 0.039 & 0.580 & 0.432 \\
16. ability to earn & 0.327 & 0.462 & 0.221 \\
24. content with current state & 0.095 & 0.177 & 0.848 \\
15. worry about future & 0.210 & 0.215 & 0.788 \\
5. mood & 0.391 & 0.044 & 0.724 \\
17. feelings of isolation & 0.189 & 0.410 & 0.616 \\
22. something to live for & 0.011 & 0.405 & 0.604 \\
\hline Cronbach's $\alpha$ & 0.8420 & 0.8316 & 0.8571 \\
\hline
\end{tabular}

physical, social and psychological QOL scores ( $<<0.05$ ), which supports the concurrent validity. Physical QOL score showed a negative correlation with the PS score; i.e., when the patient's PS was good such as PS 0 and PS 1 , the physical QOL score was high.

The Cronbach's alpha coefficient for factor 1, 2 and 3 of the QOL questionnaire was $0.84,0.83$ and 0.86 , respectively (Table 2). An analysis using the test-retest method revealed Spearman correlation coefficient of $0.55-0.89(\mathrm{p}<0.01)$ between the score of each QOL item upon admission and the score immediately before the first chemotherapy $(p<0.01)$; thus, supporting the reliability and the reproducibility of the QOL questionnaire. The published works support the reproducibility of the Egogram and STAI $(5,8,9)$.

Each of the physical, social and psychological QOL scores decreased immediately after chemotherapy, as compared to their scores before chemotherapy. Significant differences were noted in each score between the pre-chemotherapy assessment and the assessment immediately after chemotherapy, and also between the assessment immediately after chemotherapy and the assessment three weeks after chemotherapy. Thus, the sensitivity of the QOL questionnaire was supported.

The factor loadings indicate that the Egogram questionnaire can be divided into five categories: the critical parent (CP), the nurturing parent (NP), the adult (A), the free child (FC) and the adapted child (AC). Each category represents the ego state. The coefficient of correlation between each category of the Egogram
Table 3. The Coefficient of Correlation between Each Category of the Egogram and the QOL Score or STAI

\begin{tabular}{lcrlll}
\hline & CP & NP & A & FC & AC \\
\hline Physical QOL & .207 & -.029 & .086 & .032 & .123 \\
Psycho. QOL & .079 & .196 & $.616^{* *}$ & .186 & $-.435^{*}$ \\
Social QOL & .143 & .107 & $.521^{* *}$ & .214 & .275 \\
Total QOL & .221 & .162 & $.383^{*}$ & .032 & -.087 \\
\hline State Anxiety & -.252 & -.175 & $-.411^{*}$ & -.208 & $.403^{*}$ \\
Trait Anxiety & -.019 & -.265 & $-.489 * *$ & $-.423^{*}$ & $.651^{* *}$ \\
\hline
\end{tabular}

$\mathrm{n}=50, * \mathrm{p}<0.05, * * \mathrm{p}<0.01$

A: adult, AC: adapted child, CP: critical parent, FC: free child, NP: nurturing parent, STAI: State Trait Anxiety Inventory.

and the QOL score or STAI is shown (Table 3). Category A correlated with the score for social QOL, psychological QOL, state anxiety and trait anxiety. Category AC correlated with the score for psychological QOL, state anxiety and trait anxiety. The score of physical QOL showed no marked correlation with any category of the Egogram. Following these results, we carried out a further analysis paying attention to the categories $\mathrm{A}$ and $\mathrm{AC}$ of the Egogram.

The Egogram graphically represents these five categories for the purpose of assessing individual personalities. Considering the patients' rational coping ability with problems, we divided 50 patients into two groups: the A-dominant group and the other group. The A-dominant group was composed of those patients whose score for category A was higher than any other Egogram score. The other group was composed of all other patients. Changes in QOL and anxiety following chemotherapy are shown (Fig. 1). In terms of physical QOL scores, there was no significant difference between the A-dominant and the other group. However the scores of social and psychological QOL were higher in the A-dominant group at each point examined and the anxiety scores of A-dominant group were low.

Category AC was analyzed by dividing subjects into the $\mathrm{AC}<\mathrm{FC}$ group and the $\mathrm{AC}>\mathrm{FC}$ group. The course of $\mathrm{QOL}$ and state anxiety scores following chemotherapy between the $\mathrm{AC}<\mathrm{FC}$ group and the $\mathrm{AC}>\mathrm{FC}$ group is shown (Fig. 2). In the $\mathrm{AC}>\mathrm{FC}$ group, physical QOL scores changed following chemotherapy, but social and psychological QOL scores were almost unchanged. Furthermore, state anxiety levels remained high before and after chemotherapy in the $\mathrm{AC}>\mathrm{FC}$ group.

\section{Discussion}

The Egogram is based on the theory of the transactional analysis (a method of psycho-analysis) proposed by Berne (10). Heyer (8) and Dusay (11) attempted to quantify the ego state (a component of personality) in individuals and to characterize their personalities. The Egogram was developed as a result of such attempts. The validity of the Egogram has been tested (9). In Japan, Suematsu et al developed the TEG (Tokyo University type Egogram) which contains 60 questions. They confirmed 

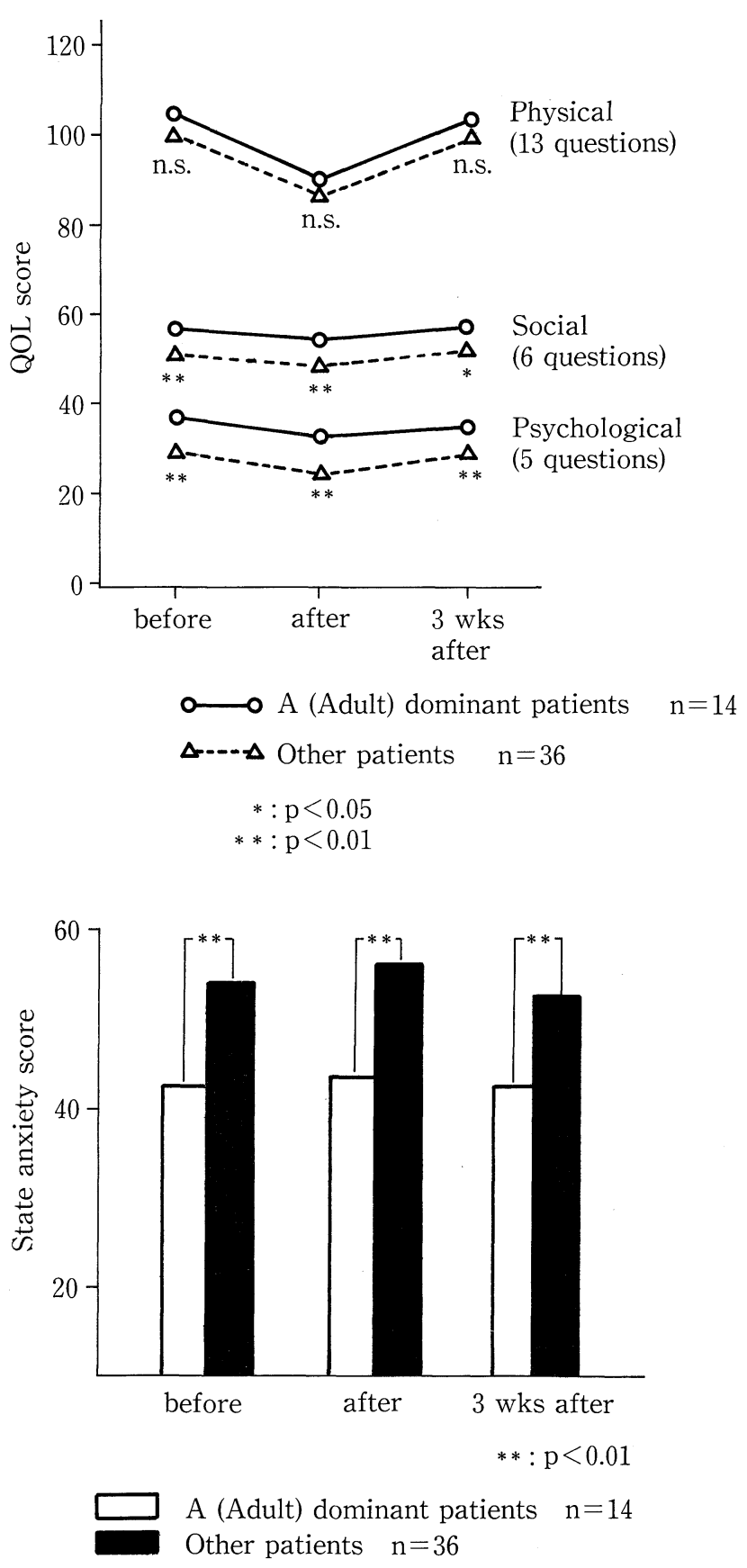

Figure 1. Comparison between A-dominant group and the other group in changes of QOL and anxiety following chemotherapy. Higher QOL scores indicate better QOL, while higher anxiety scores indicate higher anxiety levels. In terms of physical QOL scores, there was no significant difference between the Adominant group and the other group. However the scores of social and psychological QOL were higher in the A-dominant group at each point. The state anxiety score of A-dominant group remained low throughout the chemotherapy period. A: adult.

the reliability and validity of the TEG in 4,042 subjects (12). In transactional analysis, the ego state is taken to reflect the relative influence of three major components, $\mathrm{P}$ (the parent), $\mathrm{A}$ (the adult) and $\mathrm{C}$ (the child). These are correspondent to the idea of 'the superego', 'the ego' and 'the id', respectively, in psychoanalytic theory. The term 'the parent' is chosen for the ego states copied from someone else, 'the adult' is the ego states involved with realistic problem solving and 'the child' is the one which is a relic of the individual's own childhood. By using factor analysis, $\mathrm{P}$ is subdivided into $\mathrm{CP}$ and NP, $\mathrm{C}$ is subdivided into FC and AC. CP reflects the rules of society and NP nurtures and promotes growth. FC is characterized by natural and spontaneous feelings and AC engages in conforming and compromising behaviors (13). According to the predominant view, the Egogram does not change with age after the subject has reached adulthood. However, even adults sometimes show changes in their Egograms if their environment markedly changes (e.g., due to long-term illness). In the present study, the survey period was short (from the day of admission to the second cycle of chemotherapy at most), and we found no marked change in the Egograms during this survey period. To date, several Egograms have been developed in Japan. Among these, the TEG was selected for this study on the grounds that its reliability and validity had been tested in detail and that it had been used in a large number of people (about 800,000).

Anxiety can be divided into two subtypes, state and trait. State anxiety is caused by changes in the level of mental tension over short periods of time, while trait anxiety can be regarded as representing characteristics of the personality over long periods of time. In other words, state anxiety changes with time, depending on the situation to which the subject is exposed, while trait anxiety is an aspect of an individual's personality that allows us to determine the degree to which a subject is likely to have anxiety. The reliability and validity of the STAI have been confirmed by many studies (5). In the present study, the score of state anxiety changed before and after chemotherapy, while the score of trait anxiety showed little change; and the reproducibility of STAI was confirmed as compared with the score upon admission and the score immediately before the first chemotherapy.

The primary purpose of QOL assessment is to gain understanding of the state of the patient so that it can be reflected in treatments including providing support. QOL assessment can also be utilized to determine whether or not the treatment provided is appropriate. Evaluation of the results of clinical trials can be changed depending on how the QOL questionnaire is used (14). Many investigators have reported that QOL can be expressed in scientific terms and emphasized that the evaluation of QOL is essential in selecting a method of treatment $(3,15$, 16). In recent years, QOL evaluation is often carried out during clinical trials of anti-cancer agents. In 1991, the Japanese Ministry of Health and Welfare prepared guidelines concerning the methods for clinical evaluation of drugs for the treatment of malignant tumors. According to these guidelines, it is desirable that QOL assessment be carried out during phase III study, together with the assessment of anti-tumor effects, safety, survival period and survival rate (17). In the present study, QOL scores varied depending on the personalities of patients, even when their physical conditions were similar. If two different methods of treatment are provided to two groups of patients, 
QOL and Patient's Personality
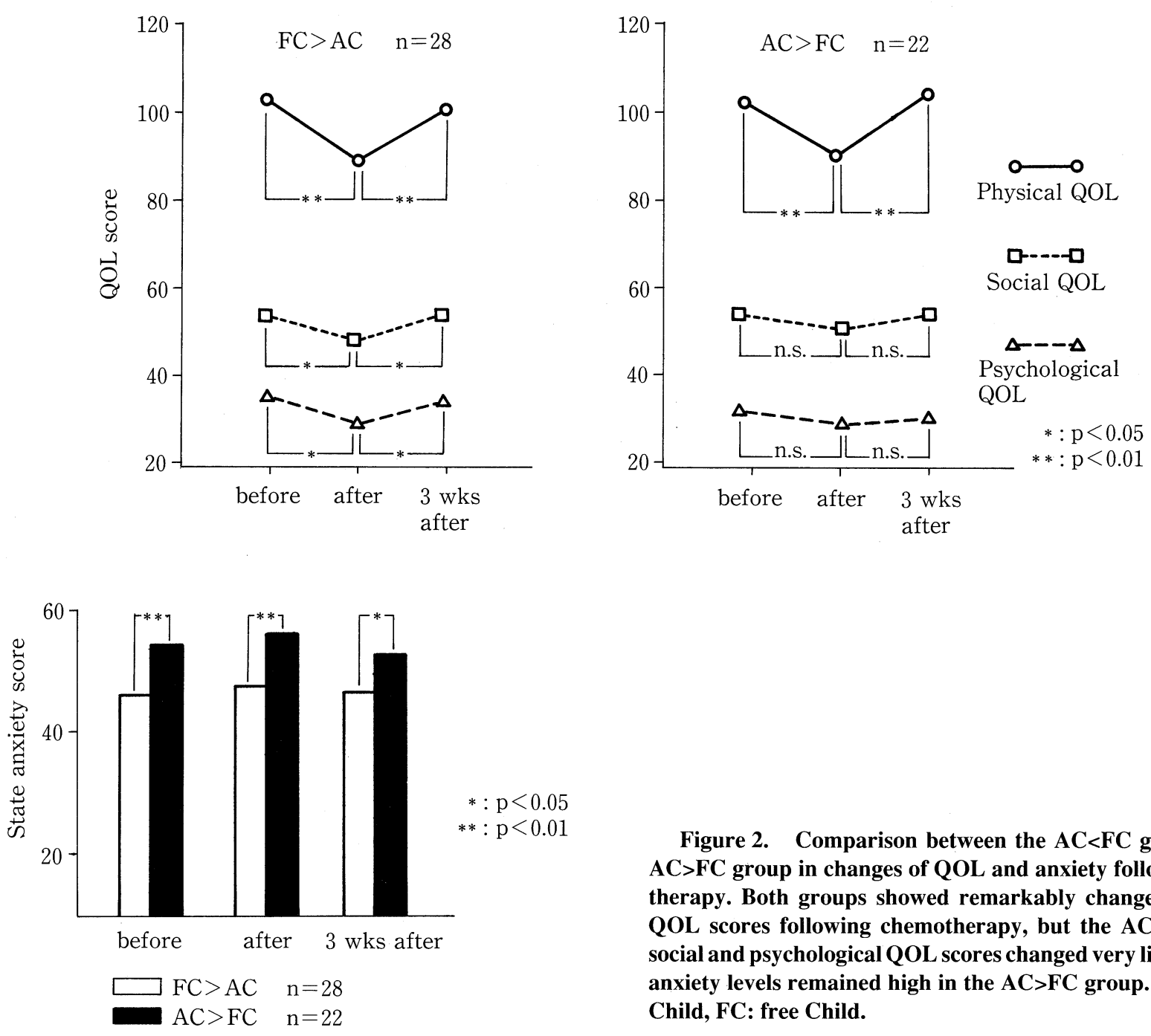

Figure 2. Comparison between the $\mathrm{AC}<\mathrm{FC}$ group and the $\mathrm{AC}>\mathrm{FC}$ group in changes of QOL and anxiety following chemotherapy. Both groups showed remarkably changes in physical QOL scores following chemotherapy, but the AC $>$ FC group's social and psychological QOL scores changed very little. The state anxiety levels remained high in the $\mathrm{AC}>\mathrm{FC}$ group. $\mathrm{AC}$ : adapted Child, FC: free Child.

resulting in no differences between the two therapies in terms of anti-tumor effects, safety or other features, excluding QOL, we should judge the superiority of one therapy over the other on the basis of the QOL assessment. The results of the present study suggest that proper assessment of the superiority of one therapy over another in such cases may not be achieved if the personalities differ between the two groups. It is therefore recommended that groups with large numbers of subjects should be used for comparing different methods of treatment. Since social and psychological QOL scores are affected by the personalities of patients, it is not appropriate directly to compare QOL scores among individuals. Hollen et al argue that the questions contained in the QOL questionnaire concerning psychological and social aspects are often cumbersome and may cloud the evaluation of therapeutic methods with invalid data. They believe that the QOL questionnaire for the assessment of the clinical efficacy of drugs should be confined to the patient's physical and functional dimensions (18). In the present study, the decrease in QOL scores immediately after chemotherapy was greater in physical QOL scores than in social and psychological QOL scores. Thus, physical QOL scores had the highest sensi-

tivity to chemotherapy. It seems reasonable, therefore, to assess QOL on the basis of physical QOL scores, if the purpose of QOL assessment is to compare different therapeutic methods.

Among respiratory diseases, chronic respiratory failure has often been a subject of study within psychosomatic medicine $(19,20)$. Several studies on the personalities of patients with chronic respiratory failure, using Egograms or the STAI, have also been published (21). Since patients with lung cancer often have long periods of illness, it seems necessary to consider the personalities of individual patients with lung cancer or the changes in the personalities of these patients. To date, there have been few studies concerning the personalities of patients with lung cancer, except some reports concerning patients at the terminal stage of lung cancer (22). In the present study, psychological and social QOL scores before and after chemotherapy were affected by the personalities of patients, suggesting that it is necessary to study the personalities of patients with lung cancer.

In the present study, A-dominant patients had higher social and psychological QOL scores and lower scores of state anxiety. According to transactional analysis, these patients are 


\section{NAKADA et al}

considered to have personalities such that they tend to view their disease more objectively and to cope more rationally with reality. The present study showed that these patients had ability to engage in rational social relationships and were discouraged less often and less markedly. That is to say, these patients' personalities correlated with their QOL scores. Regarding the course of responses on the STAI and the Egogram for patients with psychosomatic diseases before and after treatment, Ishioka et al also reported that state anxiety decreases as patients' ability to cope with reality increases (23). In our patients who belonged to the $\mathrm{AC}>\mathrm{FC}$ group, chemotherapy caused no change in their social or psychological QOL scores. These patients are considered to have personalities such that they cannot express their feelings. The present study showed that these patients were not able to express their social and psychological distress even though they might have negative experiences. These patients may tend always to make the same types of responses to questions pertaining to their physicians or to patients sharing their ward and always give conventional answers.

A survey of patients' personalities is also useful when patients need support. Because our A-dominant patients, i.e., those who can face reality directly, had high social and psychological QOL scores and low state anxiety scores, they may often be in good psychological state and have good social relationships and less anxiety. Therefore, when supporting patients, it is important to try to elicit the ego state $\mathrm{A}$ within patients so that they can try to cope with problems rationally. To this end, therapy providers should act on this basis to find concrete solutions to patients' problems.

According to transactional analysis, the $\mathrm{AC}>\mathrm{FC}$ group can be regarded as the over-adapting group (13). When considering personality as a factor in psychosomatic disorders, over-adaptation is considered to be an indicator of alexithymia. Patients who belong to this group tend to be dependent on others, disregard their own direct perceptions and sensations, and suppress emotions. Thus, particular sensitivity is needed to manage patients with high AC scores. These patients need to be guided to recognize and express needs and emotions, much like patients who tend toward alexithymia. A finding in the present study is that patients who tend to suppress their emotions (the $\mathrm{AC}>\mathrm{FC}$ patients) have higher levels of anxiety. When dealing with these patients, thereby providers should supply detailed information, be aware of patient anxiety, and attempt to reduce stress. Although therapy providers now often deal with patients without having any concrete ideas about their personalities, it is very important for them to have a clear understanding of the personalities of patients they see in daily practice. The Egogram and the STAI may provide a simple and useful means of objectively assessing the personalities of patients.

We conclude that it is important to survey the patient's personality in order to grasp his or her QOL accurately, because of its impact on the QOL assessment. Moreover, a clear understanding of the patient's personality is indispensable in providing effective patient support.

Acknowledgements: The authors would like to thank, Associate Profes- sor, Toru Hosaka for his helpful suggestions. A summary of this paper was presented at the 33rd Annual Meeting (Nagoya, 1992) and the 34th Annual Meeting (Tokyo, 1993) of the Japan Lung Cancer Society, and at the 7th World Conference on Lung Cancer (Colorado Springs, CO 1994).

\section{References}

1) Donovan K, Sanson-Fisher RW, Redman S. Measuring Quality of Life in Cancer Patients. J Clin Oncol 7: 959, 1989.

2) Schipper H. Quality of Life in Cancer Patients. Gan to Kagakuryoho (Jpn J Cancer Chemother) 17: 716, 1990 (abstract in English).

3) Schipper H, Clinch AM, McMurray A, Levitt M. Measuring the quality of life in cancer patients: The functional living index-cancer: development and validation. J Clin Oncol 2: 472, 1984.

4) Priestman TJ, Baum M. Evaluation of quality of life in patients receiving treatment for advanced breast cancer. Lancet 24: 899, 1976.

5) Nakazato K, Mizuguchi T. Development and validation of Japanese version of State-Trait Anxiety Inventory. Shinshin-Igaku (Jpn J Psychosomatic Med) 22: 107, 1982 (abstract in English).

6) Holmes S, Dickerson J. The quality of life: Design and evaluation of a self-assessment instrument for use with cancer patients. Int J Nurs Stud 24: $15,1987$.

7) Coates A, Dillenbeck CF, McNeil DR, et al. On the receiving end-II linear analogue self-assessment (LASA) in evaluation of aspects of the quality of life of cancer patients receiving therapy. Eur J Cancer Clin Oncol 19: 1633, 1983.

8) Heyer NR. Empirical research on ego state theory. Trans Anal J 17: 286, 1987.

9) Williams JE, Watson JR, Walters PA, Williams JG. Construct validity of transactional analysis ego states: Free child, adult and critical parent. Trans Anal J 13: 43, 1983.

10) Berne E. Transactional Analysis in Psychotherapy. Ballantine Books, New York, 1973, p.9.

11) Dusay JM. Egograms: How I see you and you see me. Revised version. Ikemi Y, ed. Sogensya, Osaka, 1980, p.33 (in Japanese).

12) Suematsu $H$, Wada M, Nomura $S$, Tawara R. Egogram Pattern. Kaneko Syobo, Tokyo, 1989, p.27 (in Japanese)

13) Heyer NR. Development of a questionnaire to measure ego states with some applications to social and comparative psychiatry. Trans Anal J 9: 9, 1979.

14) Schipper H, Levitt M. Measuring quality of life: Risks and benefits. Cancer Treat Rep 69: 1115, 1985.

15) Furue H. Quality of life in patients with advanced cancer. Gan to Kagakuryoho (Jpn J Cancer Chemother) 14: 1, 1987 (abstract in English).

16) Spitzer WO, Dobson AJ, Chesterman E, et al. Measuring the quality of life of cancer patients. J Chron Dis 34: 585, 1981.

17) Tsukagoshi $S$, Kurihara M, Urushizaki I. On the guideline in clinical trial of cancer chemotherapy. Ganchiryo to Syukusyu, 3: 417, 1991 (in Japanese)

18) Hollen PJ, Gralla RJ, Kris MG, Potanovich LM. Quality of life assessment in individuals with lung cancer: Testing the lung cancer symptom scale (LCSS). Eur J Cancer 29A: S51, 1993.

19) Egashira Y.Psychosomatic Approach to chronic pulmonary emphysema. Jpn J Thor Dis 25: 297, 1987 (abstract in English).

20) Hiratsuka T, Kida K. Quality of life measurements using a linear analog scale for elderly patients with chronic lung disease. Internal Medicine 32: 832, 1993.

21) Muramatsu $Y$, Kisugi $T$, Satou K, et al. The psychological change of chronic respiratory failure patients under home oxygen therapy. Kokyufuzen chousakenkyu: 44, 1989 (in Japanese).

22) Shirai S. Kangoni ikasu koryu bunseki (Transactional analysis for nursing), Igakusyoin, Tokyo, 1989, p.156 (in Japanese).

23) Ishioka A, Sasaki D, Narita N, Kawakami K, Sohma S, Kanazawa T. Changes of the scores of STAI and Egogram in the patients with psychosomatic disease before and after psychosomatic therapy. ShinshinIgaku (Jpn J Psychosom Med) 22: 337, 1982 (abstract in English). 